\title{
Off-pump coronary artery bypass grafting: For the many or the few?
}

\author{
Nishith N. Patel, BSc, MB, BCh, MRCS, and Gianni D. Angelini, MD, MCh, FRCS
}

\section{Supplemental material is available online.}

Off-pump coronary artery bypass grafting (OPCAB) without cardiopulmonary bypass has evolved during the past 2 decades and has gained popularity in many centers. Despite favorable evidence from both prospective randomized trials and large observational studies, however, the adoption of $\mathrm{OPCAB}$ has been variable both worldwide and in the United Kingdom, where it has plateaued at approximately $17 \%{ }^{1}$ Moreover, recent studies suggest that OPCAB may be associated with adverse outcomes. The goals of this editorial are to evaluate critically the current status of OPCAB in the light of recent evidence and to suggest its future direction.

\section{OFF-PUMP VERSUS ON-PUMP: IMPLICATIONS OF THE EVIDENCE}

The routine application of OPCAB is as safe as coronary artery bypass grafting with cardiopulmonary bypass (ONCAB). Meta-analyses of randomized controlled trials in low-risk patients demonstrate similar outcomes for both interventions in terms of mortality, myocardial infarction, and need for repeat revascularization at 1 and 2 years.,3 They also demonstrate that $\mathrm{OPCAB}$ is associated with reductions in the risks for stroke $(50 \%)$, atrial fibrillation $(30 \%)$, wound infection $(48 \%)$, and acute kidney injury $(70 \%) .^{3-5}$ OPCAB also reduces transfusion and inotrope requirements, ventilation time, intensive care unit and hospital stays, and in-hospital and 1-year direct costs. ${ }^{6,7}$ Our group has recently reported long term follow-up at 6 to 8 years among survivors of the BHACS-1 and BHACS2 trials. ${ }^{8}$ We found no difference in the likelihoods of graft occlusion (odds ratio [OR], 1.00; 95\% confidence interval [CI], 0.55-1.81), death (hazard ratio [HR], 1.24; 95\% CI, 0.72-2.15), major adverse cardiac-related events (HR, $0.84 ; 95 \% \mathrm{CI}, 0.58-1.24$ ) or health-related quality of life outcomes between the OPCAB and ONCAB groups.

\footnotetext{
From the Bristol Heart Institute, University of Bristol, Bristol Royal Infirmary, Bristol, United Kingdom.

Received for publication June 24, 2010; revisions received June 30, 2010; accepted for publication July 19, 2010.

Address for reprints: Gianni D. Angelini, MD, MCh, FRCS, Level 7, Queen's Building, Bristol Heart Institute, Bristol Royal Infirmary, Marlborough St, Bristol, United Kingdom BS2 8HW (E-mail: g.d.angelini@bristol.ac.uk).

J Thorac Cardiovasc Surg 2010;140:951-3

$0022-5223 / \$ 36.00$

Copyright $₫ 2010$ by The American Association for Thoracic Surgery

doi:10.1016/j.jtcvs.2010.07.045
}

The recent ROOBY trial, however, a prospective, multicenter trial with 2000 patients randomly assigned to undergo OPCAB or ONCAB during a 6 -year period, reported a $33 \%$ increase in the risk of the primary long-term composite end point of death from any cause, nonfatal myocardial infarction, or repeat revascularization within 1 year for patients undergoing $\mathrm{OPCAB}$ (relative risk, 1.33 ; 95\% CI, 1.01$1.76 ; P=.04$; number needed to cause 1 harmful event, 71 ). ${ }^{9}$

This study, however, had several major limitations. More than $70 \%$ of eligible patients (scheduled for urgent or elective coronary artery bypass grafting) were excluded because of clinical reservations of the surgical team or small target vessels. This suggests inexperience of surgeons in the trial, who were required to have performed just $20 \mathrm{OPCAB}$ procedures to participate. Conversion to ONCAB, which is known to increase morbidity and mortality, ${ }^{10,11}$ occurred in more than $12 \%$ of cases, much greater than the $1 \%$ to $3 \%$ reported by centers specializing in OPCAB. ${ }^{11,12}$ In the OPCAB group, more than $50 \%$ of patients received red blood cell transfusions, which contrasts with the $30 \%$ in previous randomized trials. ${ }^{7}$ Finally, only a small minority of the studied population were high-risk patients, a group more likely to benefit from OPCAB.

Although data from randomized trials provide the most accurate evidence, they are underpowered to demonstrate a difference in hard end points. Several large propensity-matched retrospective series and meta-analyses from centers proficient in OPCAB have provided compelling evidence in favor of the technique. A retrospective analysis of 49,830 patients from the New York state registry reported lower 30-day mortality and incidences of postoperative stroke and respiratory failure for risk-adjusted isolated $\mathrm{OPCAB}$ versus $\mathrm{ONCAB}$ surgery. ${ }^{13}$ Three-year follow-up revealed that patients who had undergone OPCAB did have a higher rate of repeat revascularization; however, survival was equivalent between the groups. ${ }^{13}$ A similar intention-to-treat analysis of 42,477 patients from the Society of Thoracic Surgeons National Adult Cardiac Surgery database showed reductions in riskadjusted mortality, stroke, perioperative myocardial infarction, renal failure, mediastinitis, need for reoperation, atrial fibrillation, and prolonged ventilation for patients in the OP$\mathrm{CAB}$ group versus the ONCAB group. ${ }^{14} \mathrm{~A}$ meta-analysis of 22 risk-adjusted (logistic regression or propensity-score) observational studies $(n=293,617)$ showed OPCAB to be associated with reduced 30-day mortality (OR, 0.72; 95\% CI, 0.66-0.78), stroke (OR, 0.62; 95\% CI, 0.55-0.69), myocardial infarction (OR, 0.66; 95\% CI, 0.50-0.88), and atrial fibrillation (OR, $0.78 ; 95 \%$ CI, $0.74-0.82) .{ }^{15}$ At 1 to 2 years, 
OPCAB was associated with trends toward reduced mortality but also increased repeat revascularization (OR, 1.35; 95\% CI, 0.76-2.39). These reports from large-volume centers suggest that OPCAB is a specialized technique requiring dedication, infrastructure, and expertise to achieve proficiency and good results.

This in turn raises 2 important questions that relate to the future direction of OPCAB. First, how should OPCAB, a specialized technique, be safely introduced into routine clinical practice? Second, what group of patients will benefit most from OPCAB?

\section{A SPECIALIZED TECHNIQUE FOR EXPERTS?}

The adoption of OPCAB has been highly variable. The reasons for this include the lack of established training programs, the perception that success with the technique is limited to more proficient surgeons, and a fear of deleterious patient outcomes, especially during the learning curve. ${ }^{16}$ In the largest review of the incorporation of OPCAB into a surgical practice $(12,540$ patients undergoing coronary artery bypass grafting, including 1915 OPCAB procedures), Mack and colleagues ${ }^{12}$ reported an increase in OPCAB from $1.2 \%$ of cases in 1995 to $34.1 \%$ of cases in 2000 (individual surgeon adoption rates ranged from $1 \%$ to $96 \%$ by 2000). Initially, OPCAB case selection considered only elective cases requiring a limited number of grafts ( 2 or 3 ) to the anterior surface of the heart, with patients in an unstable condition, those undergoing reoperation, and those requiring multiple bypasses on the lateral surface generally considered unsuitable. As surgeon experience increased along with developments in stabilizer technology, however, all patients were considered for OPCAB. The OPCAB to ONCAB conversion rate in this series was $2.9 \%$. The increased use of OPCAB was associated with a reduction in hospital mortality from $4 \%$ to $3.2 \%$ and a reduction in procedural morbidity.

In our unit, between 1997 and 2001, the proportion of OPCAB cases increased from $8 \%$ to $68 \%$ without any increase in procedural morbidity. This change was accompanied by gradual increases in the complexity of cases, number of distal anastomoses, use of multiple arterial conduits, and lateral wall revascularization. ${ }^{17,18}$

Key elements to the adoption of OPCAB are appropriate patient selection, individualized grafting strategy, peer-topeer training of the entire team, and graded clinical experience (preoperative planning, adequate exposure, proximal anastomoses to the aorta, distal anastomoses initially to anterior wall vessels, followed by inferior wall vessels and then lateral wall vessels). ${ }^{19}$ In our experience, the surgeon's learning curve is around 50 to 75 cases, and good proficiency with the technique is usually associated with a low $1 \%$ to $2 \%$ conversion rate. ${ }^{20,21}$

Where senior surgeons are experienced with the technique, OPCAB can be safely and reproducibly taught to trainees. ${ }^{17,18,21}$ Careful early case selection with later progression to more complex procedures under the tutelage of experienced trainers has been shown to permit effective training without increased morbidity, even among highrisk patients. ${ }^{17,22}$ OPCAB has been an integral part of our unit training program since the early days, with the proportion of OPCAB procedures performed by trainees increasing from $18 \%$ to $62 \%$ between the years 1999 to $2001{ }^{17,18}$ By the end of their 3rd year, residents have performed 40 to 50 multivessel OPCAB revascularizations as first surgeons under direct senior surgeon supervision. An early comparison of outcomes demonstrated no difference between patients operated on by senior surgeons or supervised trainees. ${ }^{17}$ During the last 2 years of the training program, and after satisfying the senior surgeons that they are proficient in OPCAB techniques, residents are then permitted to perform OPCAB cases without direct supervision. When the results of these unsupervised cases were reviewed, again there was no increase in patient morbidity relative to trainees operating under direct supervision. ${ }^{17}$

A major criticism of the ROOBY trial was that $55 \%$ of OPCAB cases were performed primarily by residents. ${ }^{9}$ Evidence seems strongly to suggest, however, that it is not the residents but instead the lack of experienced trainers that resulted in poor outcomes.

\section{WHAT GROUP OF PATIENTS WILL BENEFIT MOST FROM OPCAB?}

To date, all prospective randomized trials evaluating OPCAB have focused on low-risk patients or a mixed group of patients, demonstrating OPCAB to be as effective and safe as ONCAB. Observational studies, however, suggest that the greatest benefits of $\mathrm{OPCAB}$, in terms of reductions in mortality and morbidity, may be seen among high-risk patients. ${ }^{23,24}$ These include women in general and patients with a EuroSCORE greater than 5, left ventricle dysfunction, atherosclerotic aortic disease, age older than 75 years, diabetes, renal failure, left main stem disease, reoperations, chronic lung disease, emergency coronary artery bypass grafting, acute myocardial infarction, and preoperative cerebrovascular disease (see online bibliography). Currently, there are no published prospective randomized comparisons of OPCAB versus ONCAB for the treatment of high-risk patients. The recently published Best Bypass Surgery Trial claimed to evaluate 30-day outcomes in 341 high-risk patients randomly allocated to undergo either OP$\mathrm{CAB}$ or $\mathrm{ONCAB} .^{25}$ The investigators reported no significant difference in their composite primary outcome of adverse cardiac and cerebrovascular events. This trial, however, did not truly recruit high-risk patients. The exclusion criteria were previous heart surgery, left ventricular ejection fraction less than $30 \%$, unstable preoperative condition, and emergency surgery. There are currently 2 prospective randomized 
trials underway evaluating the efficacy of OPCAB in highrisk patients. The CRISP trial run by our and the Oxford unit (ISRCTN 29161170) is an international multicenter trial randomly assigning more than 5000 high-risk patients to OP$\mathrm{CAB}$ or ONCAB. The inclusion criterion is a EuroSCORE greater than 5. The design of this trial is "expertise based," with patients randomly allocated to previously specified surgeons in the same unit who favor and practice primarily OP$\mathrm{CAB}$ or ONCAB. The other is the German Off Pump Coronary Artery Bypass in Elderly Study (GOPCABE, NCT00719667), a multicenter trial randomly allocating 2000 patients older than 75 years (but excluding patients undergoing reoperative surgery) to undergo either $\mathrm{OPCAB}$ or ONCAB.

\section{CONCLUSIONS}

An overwhelming wealth of evidence demonstrates that OPCAB is a safe alternative to ONCAB, with similar outcomes for low risk patients, and that it can be safely incorporated into routine surgical practice. It is an obviously technically demanding procedure that should be performed in high-volume OPCAB centers to obtain proficiency and optimal outcomes. The greatest benefit of OPCAB is likely to be seen in high risk patients, and the results of ongoing prospective clinical trials are eagerly awaited.

The future of OPCAB remains bright and expansive. $\mathrm{OPCAB}$ is a technique for the many and not the few, both surgeons and patients, but only with structured training and supervision in the right environment.

\section{References}

1. Bridgewater B, Keogh B, Kinsman R, Walton P. Demonstrating quality: Sixth National Adult Cardiac Surgical Database Report 2008. Society for Cardiothoracic Surgery in Great Britain \& Ireland. Henley-on-Thames (UK): Dendrite Clinical Systems; 2009.

2. Feng ZZ, Shi J, Zhao XW, Xu ZF. Meta-analysis of on-pump and off-pump coronary arterial revascularization. Ann Thorac Surg. 2009;87:757-65. Erratum in: Ann Thorac Surg. 2009;87:2008

3. Møller CH, Penninga L, Wetterslev J, Steinbrüchel DA, Gluud C. Clinical outcomes in randomized trials of off- vs. on-pump coronary artery bypass surgery: systematic review with meta-analyses and trial sequential analyses. Eur Heart J. 2008;29:2601-16

4. Sedrakyan A, Wu AW, Parashar A, Bass EB, Treasure T. Off-pump surgery is associated with reduced occurrence of stroke and other morbidity as compared with traditional coronary artery bypass grafting: a meta-analysis of systematically reviewed trials. Stroke. 2006;37:2759-69.

5. Nigwekar SU, Kandula P, Hix JK, Thakar CV. Off-pump coronary artery bypass surgery and acute kidney injury: a meta-analysis of randomized and observational studies. Am J Kidney Dis. 2009;54:413-23.

6. Bainbridge D, Martin J, Cheng D. Off pump coronary artery bypass graft surgery versus conventional coronary artery bypass graft surgery: a systematic review of the literature. Semin Cardiothorac Vasc Anesth. 2005;9:105-11.
7. Cheng DC, Bainbridge D, Martin JE, Novick RJ, Evidence-Based Perioperative Clinical Outcomes Research Group. Does off-pump coronary artery bypass reduce mortality, morbidity, and resource utilization when compared with conventional coronary artery bypass? A meta-analysis of randomized trials. Anesthesiology. 2005;102:188-203.

8. Angelini GD, Culliford L, Smith DK, Hamilton MC, Murphy GJ, Ascione R, et al. Effects of on- and off-pump coronary artery surgery on graft patency, survival, and health-related quality of life: long-term follow-up of 2 randomized controlled trials. J Thorac Cardiovasc Surg. 2009;137:295-303.

9. Shroyer AL, Grover FL, Hattler B, Collins JF, McDonald GO, Kozora E, et al. On-pump versus off-pump coronary-artery bypass surgery. $N$ Engl $\mathrm{J} \mathrm{Med}$. 2009;361:1827-37.

10. Jin R, Hiratzka LF, Grunkemeier GL, Krause A, Page US 3rd. Aborted off-pump coronary artery bypass patients have much worse outcomes than on-pump or successful off-pump patients. Circulation. 2005;112(9 Suppl):I332-7.

11. Reeves BC, Ascione R, Caputo M, Angelini GD. Morbidity and mortality following acute conversion from off-pump to on-pump coronary surgery. Eur J Cardiothorac Surg. 2006;29:941-7.

12. Mack M, Bachand D, Acuff T, Edgerton J, Prince S, Dewey T, et al. Improved outcomes in coronary artery bypass grafting with beating-heart techniques. J Thorac Cardiovasc Surg. 2002;124:598-607.

13. Hannan EL, Wu C, Smith CR, Higgins RS, Carlson RE, Culliford AT, et al. Offpump versus on-pump coronary artery bypass graft surgery: differences in short-term outcomes and in long-term mortality and need for subsequent revascularization. Circulation. 2007;116:1145-52.

14. Puskas JD, Edwards FH, Pappas PA, O’Brien S, Peterson ED, Kilgo P, et al. Offpump techniques benefit men and women and narrow the disparity in mortality after coronary bypass grafting. Ann Thorac Surg. 2007;84:1447-56.

15. Wijeysundera DN, Beattie WS, Djaiani G, Rao V, Borger MA, Karkouti K, et al. Off-pump coronary artery surgery for reducing mortality and morbidity: metaanalysis of randomized and observational studies. J Am Coll Cardiol. 2005;46: 872-82.

16. Murphy GJ, Rogers CA, Caputo M, Angelini GD. Acquiring proficiency in offpump surgery: traversing the learning curve, reproducibility, and quality control. Ann Thorac Surg. 2005;80:1965-70.

17. Caputo M, Bryan AJ, Capoun R, Mahesh B, Ciulli F, Hutter J, et al. The evolution of training in off-pump coronary surgery in a single institution. Ann Thorac Surg. 2002;74:S1403-7.

18. Caputo M, Chamberlain MH, Ozalp F, Underwood MJ, Ciulli F, Angelini GD Off-pump coronary operations can be safely taught to cardiothoracic trainees. Ann Thorac Surg. 2001;71:1215-9.

19. Halkos ME, Puskas JD. Teaching off-pump coronary artery bypass surgery. Semin Thorac Cardiovasc Surg. 2009;21:224-8.

20. Rogers CA, Reeves BC, Caputo M, Ganesh JS, Bonser RS, Angelini GD. Control chart methods for monitoring cardiac surgical performance and their interpretation. J Thorac Cardiovasc Surg. 2004;128:811-9.

21. Caputo M, Reeves BC, Rogers CA, Ascione R, Angelini GD. Monitoring the performance of residents during training in off-pump coronary surgery. $J$ Thorac Cardiovasc Surg. 2004;128:907-15.

22. Ascione R, Reeves BC, Pano M, Angelini GD. Trainees operating on high-risk patients without cardiopulmonary bypass: a high-risk strategy? Ann Thorac Surg. 2004;78:26-33.

23. Al-Ruzzeh S, Nakamura K, Athanasiou T, Modine T, George S, Yacoub M, et al Does off-pump coronary artery bypass (OPCAB) surgery improve the outcome in high-risk patients?: a comparative study of 1398 high-risk patients. Eur J Cardiothorac Surg. 2003;23:50-5.

24. Puskas JD, Thourani VH, Kilgo P, Cooper W, Vassiliades T, Vega JD, et al. Offpump coronary artery bypass disproportionately benefits high-risk patients. Ann Thorac Surg. 2009;88:1142-7.

25. Møller CH, Perko MJ, Lund JT, Andersen LW, Kelbaek H, Madsen JK, et al. No major differences in 30-day outcomes in high-risk patients randomized to offpump versus on-pump coronary bypass surgery: the best bypass surgery trial. Circulation. 2010;121:498-504. 


\section{Online Bibliography}

1. Mishra M, Malhotra R, Karlekar A, Mishra Y, Trehan N. Propensity casematched analysis of off-pump versus on-pump coronary artery bypass grafting in patients with atheromatous aorta. Ann Thorac Surg. 2006;82:608-14.

2. Demaria RG, Carrier M, Fortier S, Martineau R, Fortier A, Cartier R, et al. Reduced mortality and strokes with off-pump coronary artery bypass grafting surgery in octogenarians. Circulation. 2002;106(12 Suppl. 1):I5-10.

3. Magee MJ, Dewey TM, Acuff T, Edgerton JR, Hebeler JF, Prince SL, et al Influence of diabetes on mortality and morbidity: off-pump coronary artery bypass grafting versus coronary artery bypass grafting with cardiopulmonary bypass. Ann Thorac Surg. 2001;72:776-81.

4. Sajja LR, Mannam G, Chakravarthi RM, Sompalli S, Naidu SK, Somaraju B, et al. Coronary artery bypass grafting with or without cardiopulmonary bypass in patients with preoperative non-dialysis dependent renal insufficiency: a randomized study. J Thorac Cardiovasc Surg. 2007;133:378-88.

5. Virani SS, Lombardi P, Tehrani H, Masroor S, Yassin S, Salerno T, et al. Offpump coronary artery grafting in patients with left main coronary artery disease. J Card Surg. 2005;20:537-41.
6. Chamberlain MH, Ascione R, Reeves BC, Angelini GD. Evaluation of the effectiveness of off-pump coronary artery bypass grafting in high-risk patients: an observational study. Ann Thorac Surg. 2002;73:1866-73.

7. Halkos ME, Puskas JD, Lattouf OM, Kilgo P, Guyton RA, Thourani VH. Impact of preoperative neurologic events on outcomes after coronary artery bypass grafting. Ann Thorac Surg. 2008;86:504-10.

8. Biancari F, Mahar MA, Mosorin M, Heikkinen J, Pokela M, Taskinen P, et al. Immediate and intermediate outcome after off-pump and on-pump coronary artery bypass surgery in patients with unstable angina pectoris. Ann Thorac Surg. 2008;86:1147-52.

9. Fattouch K, Guccione F, Dioguardi P, Sampognaro R, Corrado E, Caruso M, et al. Off-pump versus on-pump myocardial revascularization in patients with STsegment elevation myocardial infarction: a randomized trial. J Thorac Cardiovasc Surg. 2009; 137:650-7.

10. Puskas JD, Kilgo PD, Kutner M, Pusca SV, Lattouf O, Guyton RA. Off-pump techniques disproportionately benefit women and narrow the gender disparity in outcomes after coronary artery bypass surgery. Circulation. 2007;116(11 Suppl):I192-9. 